\title{
Shunt Active Power Filter with Dynamic Output Current Limitation
}

\author{
R. Pregitzer, J. G. Pinto, Luís F.C. Monteiro, João L. Afonso \\ Industrial Electronics Department \\ University of Minho \\ Guimarães, Portugal \\ Email: \{rpregitzer|gpinto|Imonteiro|jla\}@dei.uminho.pt
}

\begin{abstract}
This paper presents a Shunt Active Filter with a controller able to dynamically limit the output current, which allows an effective protection of the inverter semiconductors without diminishing the active filter performance. The control strategy is based on the $p-q$ Theory expanded for three-phase four-wire systems and the power stage of the active filter is composed by a two-level four-leg inverter. Simulation results on PSCAD ${ }^{\circledR} /$ EMTDC $^{\mathrm{TM}}$ are presented to demonstrate the performance of the dynamic current limitation.
\end{abstract}

Keywords - Active Power Filter, Instantaneous Power Theory, Digital Signal Processing, Computer Simulations, Power Quality.

\section{INTRODUCTION}

The increasing use of rectifiers, thyristor power converters, arc furnaces, switched power supplies and other non linear loads is known to cause serious problems in electric power systems. These problems can be partially solved with the use of passive filters. However, this kind of filtering cannot adapt to variations of the loads, and they also can produce undesired resonances. One solution to avoid resonance problems is the shunt active power filter [1].These filters work as current sources, connected in parallel with the electric grid, and they are capable of providing the harmonics and the power factor required by the loads. Three phase four wire active filters are also capable of compensating unbalance in order to minimize the neutral current [2]. This way, the mains only supply the fundamental, balanced currents with an unitary power factor, avoiding problems in the transmission lines.

This paper appears in sequence of the work developed in the power electronics and actuators laboratory of the University of Minho (Portugal) that have as a main objective to develop a shunt active power filter prototype that will be used to demonstrate the applicability and advantage of these kind of equipments in an industrial environment. Two of the most important aspects when an equipment prototype is installed in an industrial environment are security and reliability. The security of the human operators, the security of the industry plant and the integrity of the equipment are factors that must be evaluated carefully. Therefore it is very important to protect the active power filter against phenomena that usually do not exist in a laboratory environment, but may occur in the industry.

Although the presented results are achieved from simulation, the presented strategy will be implemented in the hardware prototype that is in improvement phase. From previous experiences it is possible to verify that if the simulation model is accurately modeled and the details of hardware implementation are taken into consideration, the simulation results are very similar to the ones measured in the developed prototype [3].

A summary involving the major topics of this paper is described as follows: aspects related to the configuration of the proposed active power filter are detailed in Section II, a set of equations describing the control system based on the instantaneous power theory for three-phase four-wire systems are presented in Section III, and in Section IV the simulation parameters are introduced. The proposed system is analyzed by means of simulation results on PSCAD ${ }^{\circledR} /$ EMTDCTM $^{\text {Tn }}$ Section V. Finally, conclusions and suggestions for further works are presented in Section VI.

\section{ACtive Power FiLter CONFIGURATION}

The power stage of the Active Power Filter (Fig. 1) is composed by a standard two-level Voltage Source Inverter that uses eight IGBTs and a capacitor at the dc side.

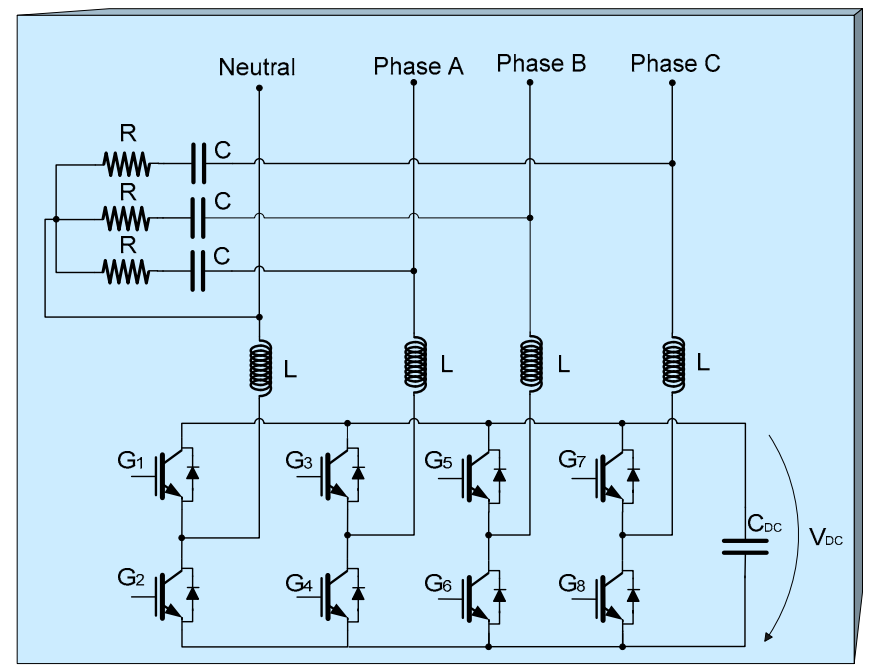

Fig. 1. Two level, four leg inverter configuration 
The capacitor voltage can be kept constant by a control algorithm that exchanges the required energy from the electric grid. The inductances are used to connect the inverter to the electric grid and the RC filters are tuned to minimize the transmission of noise due to the switching of the semiconductors.

The developed prototype uses IGBTs with a maximum collector current of $100 \mathrm{~A}$ and $\mathrm{V}_{\mathrm{CE} 0}=1700 \mathrm{~V}$ controlled by a four-phase PWM switching technique using a $16 \mathrm{kHz}$ triangular carrier (Fig. 2). Only a proportional gain $k_{p}$ is used, because this way the response of the active filter is improved when it is compensating loads with a high harmonic content. Details regarding the tuning of this controller can be found in [4].

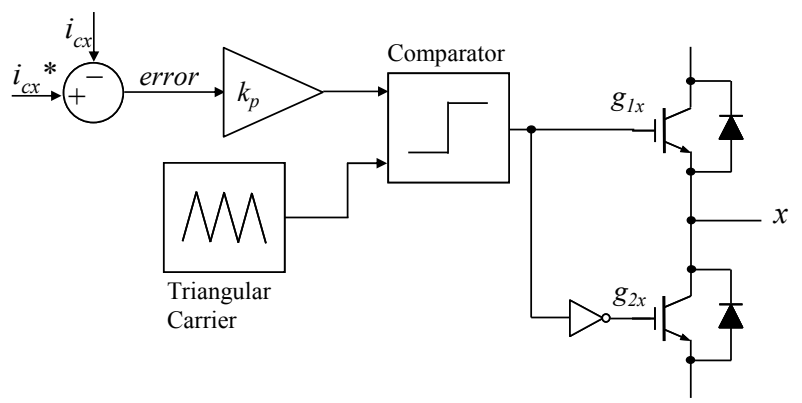

Fig. 2. PWM switching technique, without integral gain.

The coupling between the inverter and the electric grid is made by $1,5 \mathrm{mH}$ inductors. In order to attenuate the high-frequency noise, RC passive filters with a cutoff frequency of about $4 \mathrm{kHz}$ are used.

\section{THE CONTROL STRATEGY}

The strategy applied in the active power filter control is based on the p-q Theory. This theory was introduced by Akagi et al. [5] and expanded to three-phase four-wire systems by Aredes et al. [6]. It consists in an algebraic transformation (Clarke transform) of the three-phase voltages and currents in the $a-b-c$ coordinates to the $\alpha-\beta-0$ reference frame.

After the transformation, the $\mathrm{p}-\mathrm{q}$ theory components are achieved by the expressions (1-3), where $p$ is the instantaneous real power, $q$ is the instantaneous imaginary power (by definition) and $p_{0}$ is instantaneous zero-sequence power.

$$
\begin{aligned}
& p=v_{\alpha} \cdot i_{\alpha}+v_{\beta} \cdot i_{\beta} \\
& q=v_{\beta} \cdot i_{\alpha}-v_{\alpha} \cdot i_{\beta} \\
& p_{0}=v_{0} \cdot i_{0}
\end{aligned}
$$

Each one of the instantaneous powers can be separated into an average value and an oscillating value. The physical meaning of each of the instantaneous powers is:
- $\bar{p}$ - average value of the instantaneous real power $p$. Corresponds to the energy per time unit transferred from the source to the load, in a balanced way through the 3 phases;

- $\quad \tilde{p}$ - Oscillating value of the instantaneous real power. It is the energy per time unity that is exchanged between the power source and the load, through the 3 phases;

- $\quad q$ - The instantaneous imaginary power, $\mathrm{q}$, has to do with power (and corresponding undesirable currents) that is exchanged between the system phases, and which does not imply any transference or exchange of energy between the power source and the load;

- $\quad \bar{p}_{0}-$ Mean value of the instantaneous zero-sequence power. It corresponds to the energy per time unity that is transferred from the power source to the load through the zero-sequence components of voltage and current;

- $\quad \tilde{p}_{0}$ - Oscillating value of the instantaneous zero-sequence power. It means the energy per time unity that is exchanged between the power source and the load through the zero-sequence components of voltage and current.

In addition to the standard powers, there is also a component, $p_{\text {reg }}$, which is used to regulate the capacitor voltage in the dc side of the active power filter.

$$
p_{\text {reg }}=k_{p}\left(V_{r e f}^{2}-V_{D C}^{2}\right)
$$

The instantaneous powers that will be injected by the Shunt Active Filter, $p x$ and $q x$, are composed by the undesired components (harmonics, unbalance and reactive power).

$$
\begin{aligned}
& p_{x}=\widetilde{p}-\bar{p}_{0}-p_{\text {reg }} \\
& q_{x}=q
\end{aligned}
$$

Finally, it is possible to calculate the reference currents, in the $\alpha-\beta-0$ coordinates, by applying the expressions (7) and (8). The reference currents are then translated to the $a-b-c$ reference frame through the inverse Clarke transform.

$$
\begin{aligned}
& {\left[\begin{array}{l}
i_{c \alpha} \\
i_{c \beta}
\end{array}\right]=\frac{1}{v_{\alpha}^{2}+v_{\beta}^{2}} \cdot\left[\begin{array}{cc}
v_{\alpha} & v_{\beta} \\
-v_{\beta} & v_{\alpha}
\end{array}\right] \cdot\left[\begin{array}{l}
p_{x} \\
q_{x}
\end{array}\right]} \\
& i_{c 0}=i_{0}=\frac{1}{\sqrt{3}} \cdot\left(i_{a}+i_{b}+i_{c}\right)
\end{aligned}
$$

The average values of the instantaneous real power and the instantaneous zero-sequence power are calculated using a sliding window, instead of the usual Butterworth filters. 


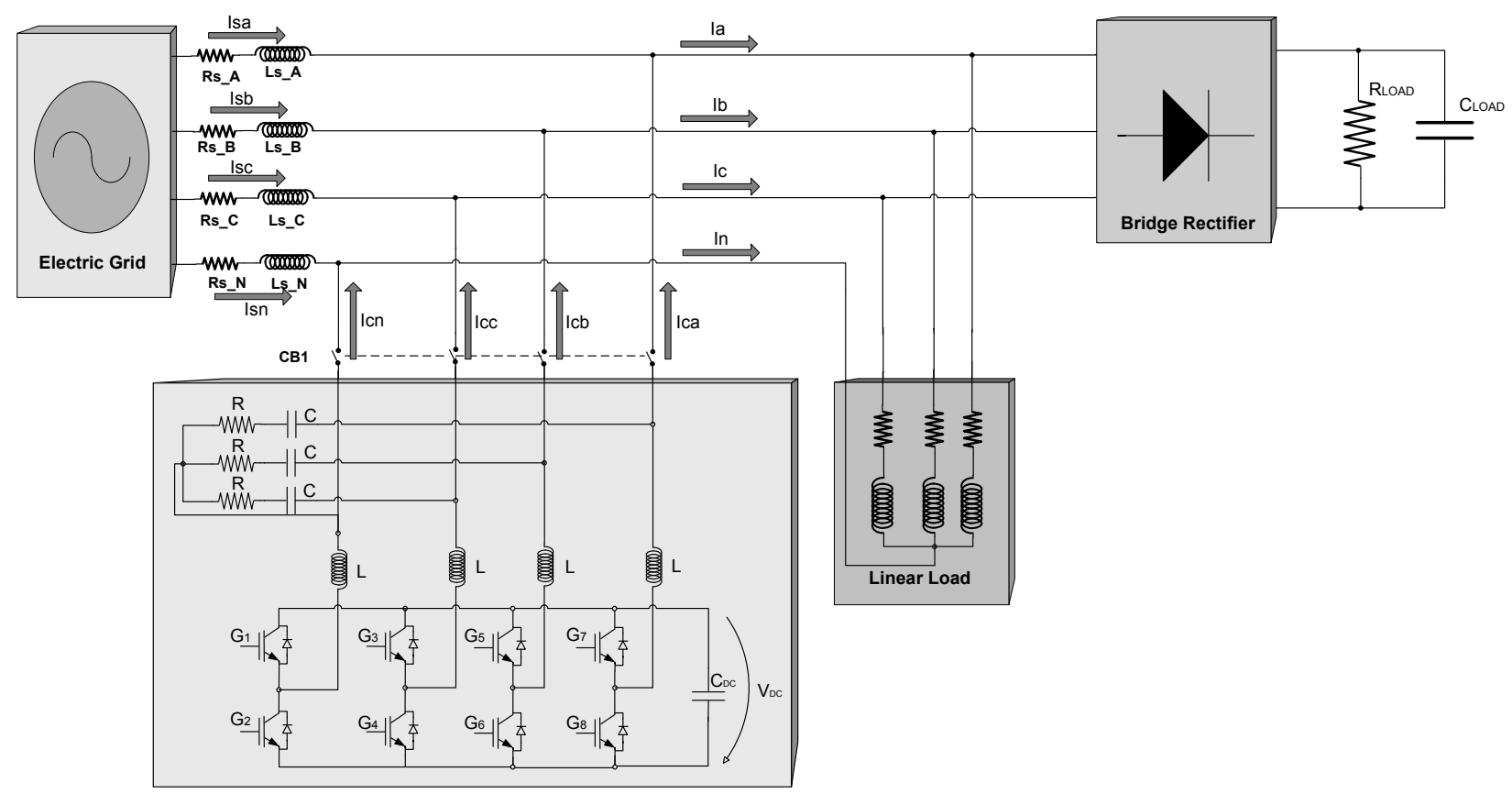

Fig. 3. Electrical system to test the Shunt Active Filter

Usually, when using a sliding window, it is necessary to have a whole cycle $(20 \mathrm{~ms}$ on the $50 \mathrm{~Hz}$ system) of information in order to determine the average value of a given variable. However, depending on the characteristics of the loads, it is possible to use a sliding window that requires only the values of half a cycle or even just one third or one sixth of the cycle.

In this specific case, where unbalance is present, the sliding window requires half a cycle. More information regarding this topic can be found on [7].

In terms of implementation, using a sliding average has the advantage that the calculation is very simple and requires only an array with the values of the last $10 \mathrm{~ms}$. Other simplifications were done, namely by expanding the calculations of the $p-q$ Theory in order to remove square roots and other mathematical operations that a fixed point microprocessor unit is not efficient at.

Another important part consists in compensating the delays produced by the control system, by exploring the half wave symmetry of the reference currents, otherwise when the load currents change fast, the source currents will have notches that will increase the THD [8].

\section{SimULATION PARAMETERS}

A test case was conceived to analyze the performance of the proposed system through digital simulations, with PSCAD $^{\circledR} /$ EMTDC $^{\mathrm{TM}} 4.2$.

In order to get realistic simulation results, all the blocks of the control strategy are discretized, and are introduced delays, fixed point variables, errors in analogue to digital conversions according to the electronic components used in the hardware implementation of the active filter [9].
In terms of hardware components, the diodes, IGBTs and transformers were modeled according to the datasheets of the real components of the laboratory prototype, and care was taken in order to accurately model the passive components.

In Fig. 3 it is possible to see the electric circuit used in simulations. This circuit is composed by an unbalanced $R L$ linear load with the characteristics presented in Table I and by a diode bridge rectifier with a $\mathrm{RC}$ load in the dc side $(\mathrm{R}=18 \Omega, \mathrm{C}=800 \mu \mathrm{F})$.

TABLE I

LINEAR LOAD CHARACTERISTICS

\begin{tabular}{|c|c|c|c|c|}
\hline & Phase a & Phase b & Phase c & Neutral \\
\hline $\mathrm{R}$ & $0,5 \Omega$ & $10,2 \Omega$ & $5,3 \Omega$ & --- \\
\hline $\mathrm{L}$ & $0,03 \mathrm{H}$ & $0,2 \mathrm{H}$ & $0,2 \mathrm{H}$ & --- \\
\hline Current & $24,3 \mathrm{~A}$ & $3,6 \mathrm{~A}$ & $3,6 \mathrm{~A}$ & $20,9 \mathrm{~A}$ \\
\hline Power Factor & 0,08 & 0,16 & 0,11 & --- \\
\hline
\end{tabular}

The voltages shown in Fig. 4 have a $6 \%$ THD and a $1.6 \%$ unbalance because of the source impedance, composed by a resistance and an inductance.

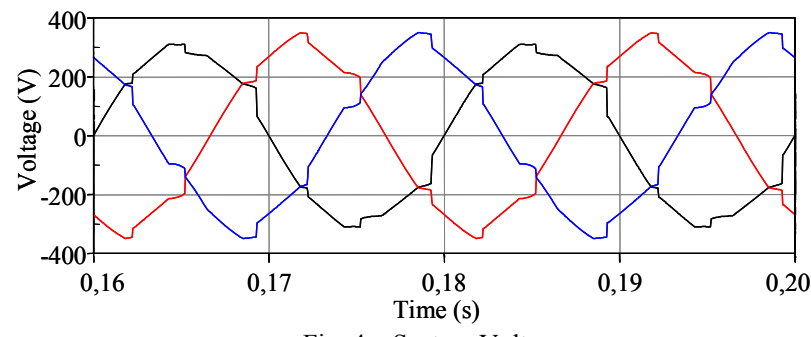

Fig. 4 - System Voltages 
Fig. 5 shows the source currents and its harmonic contents before the connection of the active power filter.
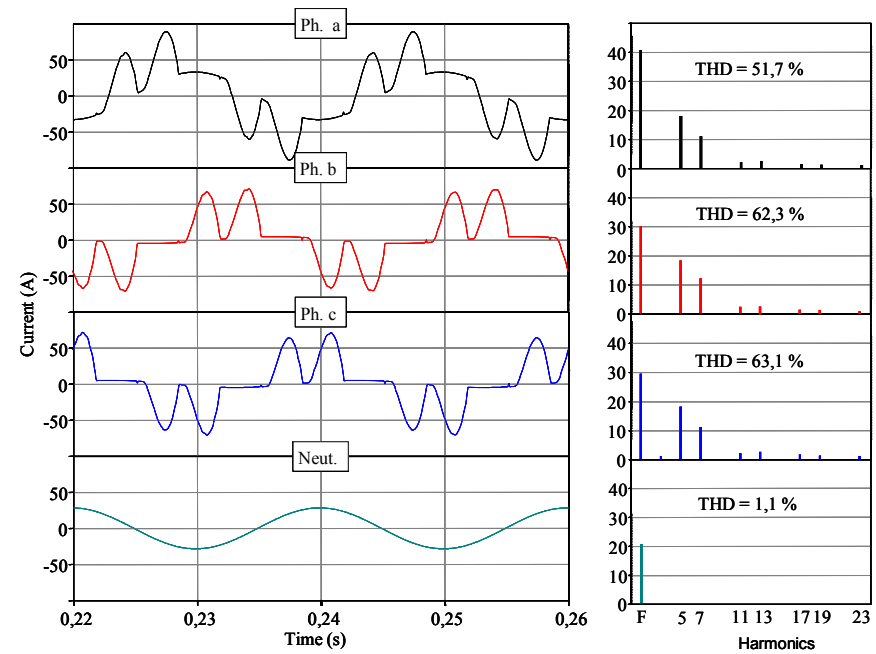

Fig. 5 - Load Currents

\section{Simulation Results}

The first test consists in evaluating the system behavior when the active power filter is connected to the system operating in steady state, and the following tests show the performance when the filter starts compensating the non-linear load. The analysis will happen with various versions of the control strategy.

\section{A. Steady State Performance}

In Fig. 6 it is possible to see the source currents and the harmonic contents when the Shunt Active Filter is compensating the load currents in steady state. The THD in all the three phases is lower than $4 \%$. The power factor and the current unbalance are also compensated and therefore the neutral current is practically zero.

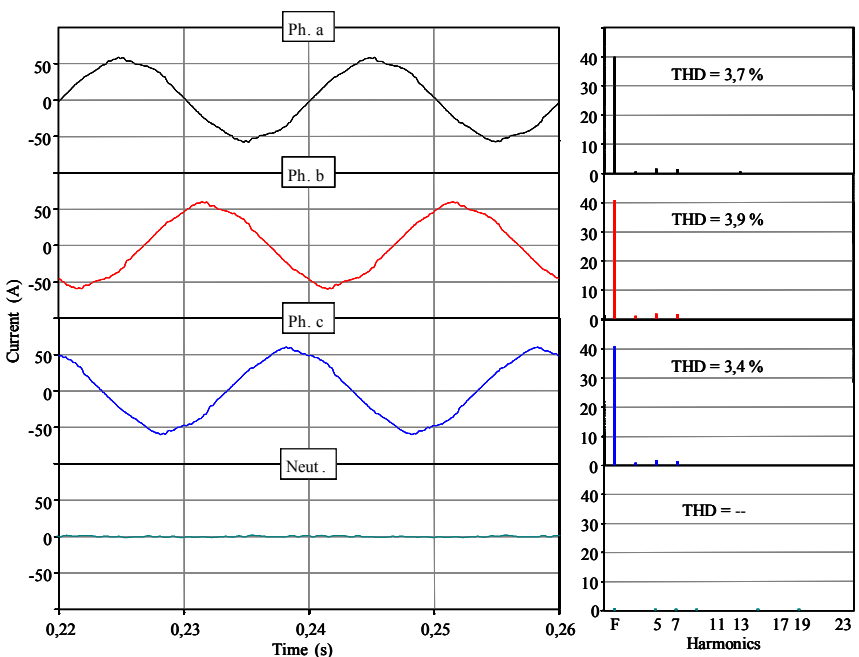

Fig. 6 - Source currents when the Shunt Active Filter is in steady state.

\section{B. Connection of a Non-Linear Load Without Current Limitation}

The initial control strategy used does not apply any kind of current limitation. If the non-linear load is connected while the Shunt Active Filter is compensating the control theory will try to compensate the transient that occurs because of the load connection. In Fig. 7 it is possible to see the load currents when the non linear load is connected at $0.21 \mathrm{~s}$. It can be seen that the current transient is very high because there is no soft-start, however this was done in order to effectively test the control algorithm for limitation of the inverter current.

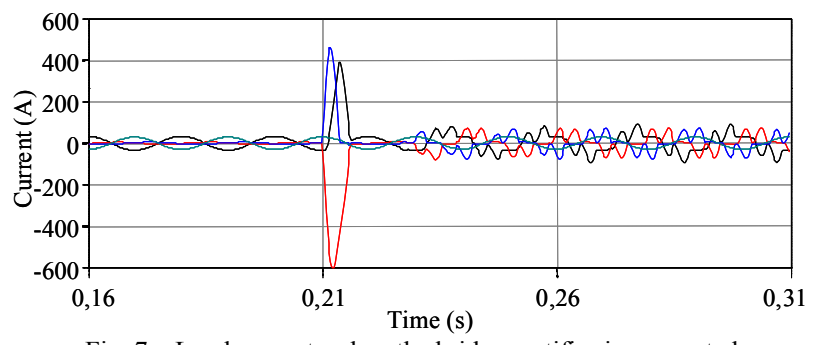

Fig. 7 - Load currents when the bridge rectifier is connected

The transient period lasted approximately $10 \mathrm{~ms}$ and during this time the load currents reach values up to $600 \mathrm{~A}$. Fig 8 shows that the filter attempts to respond to this transient, however by looking at Fig 9 it is possible to see that the hardware doesn't have the ability to produce currents with a slew rate sufficiently high to compensate this problem.

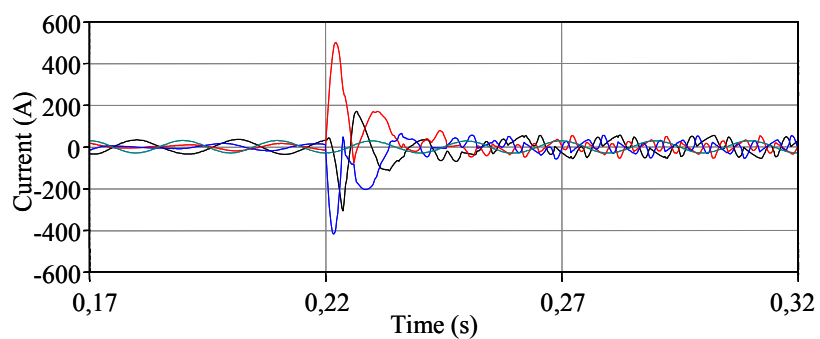

Fig. 8 - Compensation currents calculated by the controller

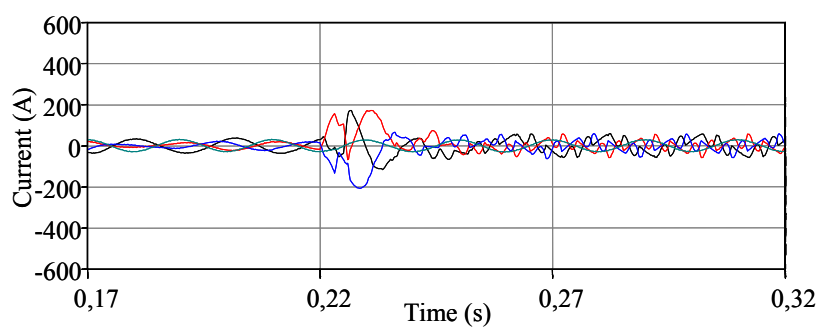

Fig. 9 - Compensation currents produced by the active power filter

Although the currents injected by the active power filter are significantly smaller than the currents calculated by the controller (Fig. 8 and Fig. 9), its value clearly exceeds the maximum allowed by the power inverter IGBTs. In the real hardware this fact could damage the inverter, or at least it the active power filter protections would trip, which would disrupt the compensation. 
The transient caused by the connection of the non linear load also causes instability in the dc side of the active filter inverter. In Fig. 10 it is possible to see the voltage waveform at the dc side of the filter inverter. Until the connection of the active filter, the dc voltage is stable around $520 \mathrm{~V}$. When the active filter is turned on at $0.14 \mathrm{~s}$ the dc voltage increases and after the initial transient period remains stable around $800 \mathrm{~V}$. At $0.21 \mathrm{~s}$ the connection of the non-linear load causes a large oscillation and the dc voltage reaches values greater than $1000 \mathrm{~V}$. This high de voltage also trips the active power filter protections and can damage the dc side capacitor or the semiconductors.

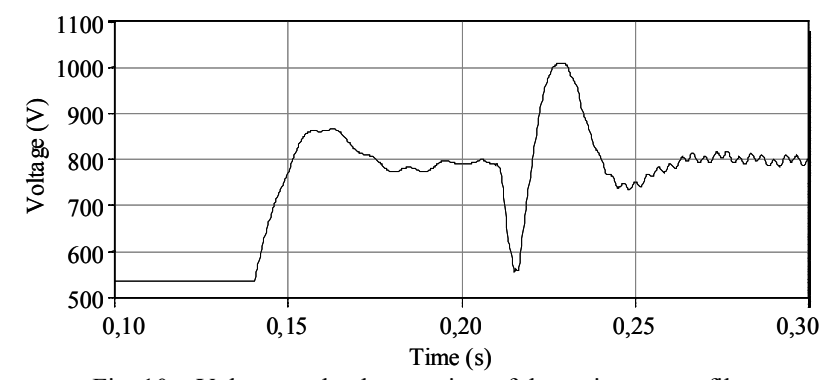

Fig. 10 - Voltage at the dc capacitor of the active power filter

\section{Connection of the Non-Linear Load with a Simple Limitation Technique}

To mitigate the problems caused by the transients occurred during the connection and disconnection of non linear loads in the facility it is necessary to upgrade the controller. A very simple algorithm that limits the maximum reference currents at $95 \%$ of the maximum value allowed by the inverter IGBTs was implemented. This was done by means of a hard limiter. In this simulation the active power filter is already running when the non linear load is connected at $0.21 \mathrm{~s}$. Fig. 11 shows the reference currents calculated by the filter controller. In this figure it is perfectly visible the limitations applied to the reference currents.

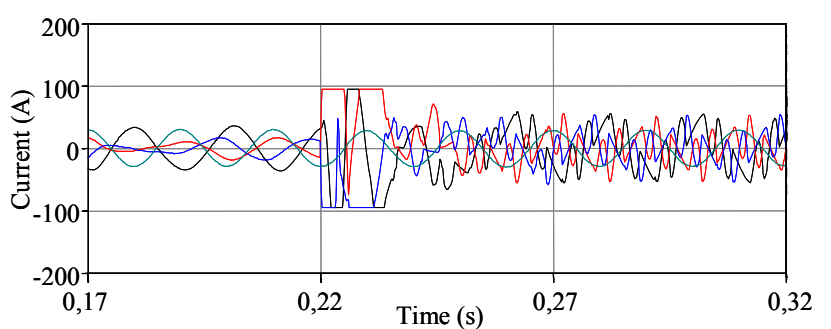

Fig. 11 - Compensation currents calculated by the controller

In Fig. 12 the currents produced by the active power filter are presented. Although the limitation applied to the reference currents was implemented, the active filter currents exceeds the value of $100 \mathrm{~A}$ allowed by the active filter IGBTs.

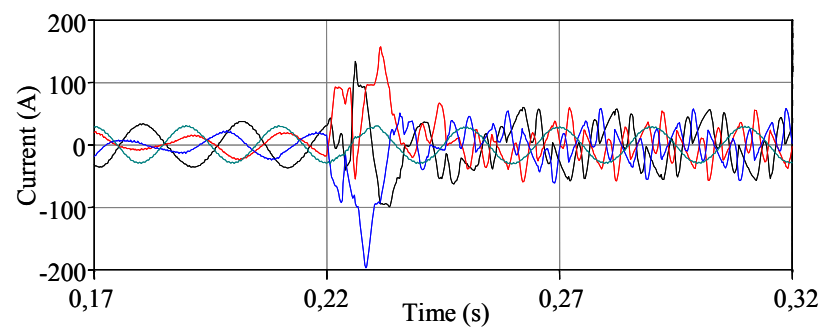

Fig. 12 - Compensation currents produced by the active power filter

As it is possible to see in Fig. 13, in the dc side of the filter the problem remains unsolved. The dc voltage reaches values of about $1000 \mathrm{~V}$, and the time that the voltage requires to stabilize is the same as before.

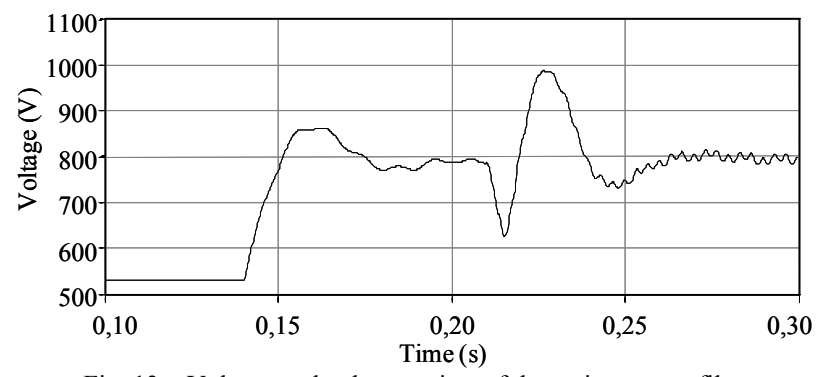

Fig. 13 - Voltage at the dc capacitor of the active power filter

\section{Connection of the Non-Linear Load with Dynamic Current Limitation}

As it can be concluded by the previous simulation, the limitation of the current is not a very simple task and requires some special attention. Since the delay compensation delays the active filter response by a half cycle, it is possible to use this time to determine the highest peak values between the four compensation currents calculated by the controller. Once the highest value is determined it is a simple matter to determine how much all the reference signals should be attenuated in order to prevent an overcurrent at the inverter. Fig. 14 shows that the reference currents are now below the maximum currents allowed at the inverter, and Fig 15 demonstrates that the inverter current follows the reference, keeping the current below $100 \mathrm{~A}$.

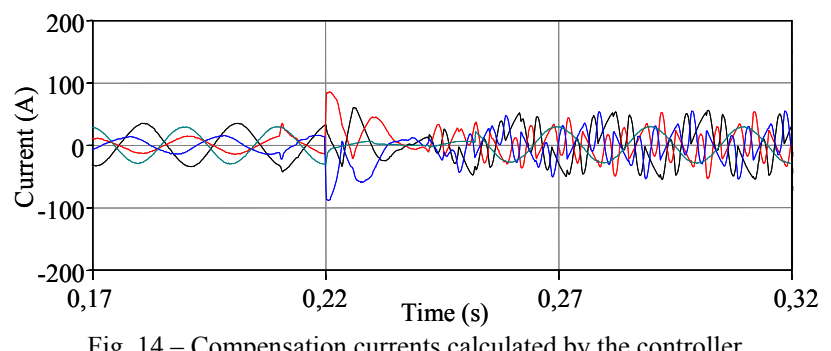

Fig. 14 - Compensation currents calculated by the controller 


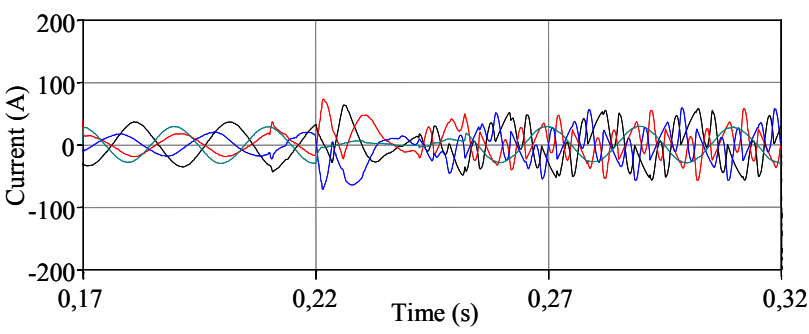

Fig. 15 - Compensation currents produced by the active power filter

The dc voltage is also more stable with the current limitation. It is possible to see on Fig. 16 that the dc voltage has a smaller transient in terms of amplitude and also in terms of length.

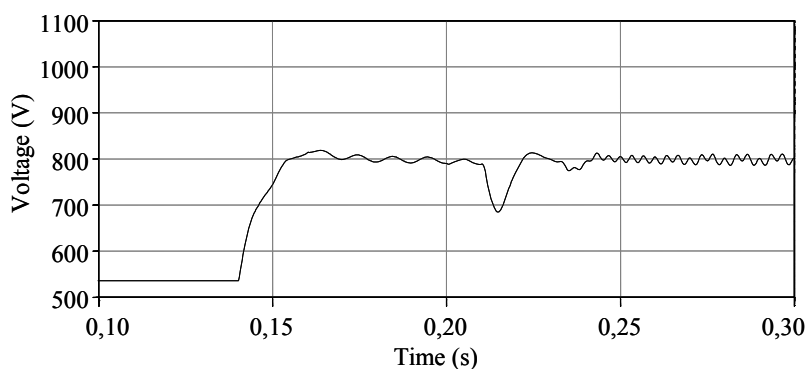

Fig. 16 - Voltage at the dc capacitor of the active power filter

When the Shunt Active Filter reaches stability, the source currents will be exactly like the ones shown in Fig. 6 .

\section{CONCLUSIONS AND SUGGESTIONS FOR FUTURE WORKS}

A strategy to dynamically limit the output currents of an active power filter was presented. The simulation results show a good performance of the Shunt Active Filter, when the load currents have a very high current transient. This strategy can be improved, because ideally the limitation should be made on the compensation powers $p_{x}$ and $q_{x}$.

In future work the current limitation will be controlled directly through the limitation of the compensation powers ( $p x$ and $q x$ ). This way the limitation strategy will be more complex because each one of the output currents depends of the combination of the two powers and is necessary to limit both values simultaneously.
On the other hand with this technique it will be possible to limit only certain power components, keeping others fully compensated. For instance, for an industry it will be usually more important to compensate the power factor and therefore, if the active filter is overloaded, all the other power components could be limited, except for the one responsible for the power factor.

\section{ACKNOWLEDGMENT}

This work was supported by the FCT (Fundação para a Ciência e a Tecnologia), project funding POCTI/ESE/41170/2001 and POCTI/ESE/48242/2002. The authors are also grateful to PRIME (Programa de Incentivos à Modernização da Economia) for funding the Project SINUS.

Luís F. C. Monteiro is grateful to Alban program for supporting his education project at the University of Minho.

\section{REFERENCES}

[1] L. Gyugi and E. C. Strycula, "Active AC Power Filters", IEEE-IAS Annual Meeting Record, 1976, pp. 529-535.

[2] Verdelho, P., Marques, G., An Active Power Filter and Unbalanced Current Compensator, IEEE Trans. Ind. Electronics, vol. 44, no. 3, June 1997, pp. 321-328.

[3] R. Pregitzer, J.C. Costa, Júlio S. Martins, J. L . Afonso, "Simulation and Implementation Results of a 3 Phase 4 Wire Shunt Active Power Filter", CDROM Proceedings of the ICHQP 2006 - International Conference on Harmonics and Quality of Power, Cascais, Portugal, 1-5 October 2006.

[4] S. Buso; L. Malesani; P. Mattavelli; Comparison of Current Control Techniques for Active Filter Applications; IEEE Transactions on Industrial Electronics, vol. 45, Issue 5, Oct. 1998; Page(s):722 - 729.

[5] H. Akagi, Y. Kanazawa, A. Nabae, "Generalized Theory of the Instantaneous Reactive Power in Three-Phase Circuits", IPEC'83 - Int. Power Electronics Conf., Tokyo, Japan, 1983, pp. 1375-1386.

[6] M. Aredes; E. H. Watanabe; "New Control Algorithms for Series and Shunt Three-Phase Four-Wire Active Power Filters"; IEEE Transactions on Power Delivery, vol. 10, no. 3, Jul. 1995; pp.: 1649-1656.

[7] J. L. Afonso; M. J. S. Freitas; J. S. Martins; p-q Theory Power Components Calculations; 2003 IEEE International Symposium on Industrial Electronics, ISIE '03, vol. 1, 9-11 Jun. 2003; pp.: 385 - 390.

[8] J. L. Afonso, "Filtro Activo Paralelo com Controlo Digital para Melhoria da Qualidade de Energia Eléctrica", Ph.D. dissertation, Dept. Industrial Electronics, Univ. Minho, Portugal, 2000.

[9] R. Pregitzer; Computer Simulations of Active Power Filters in Real Operating Conditions; MSc. Thesis (in Portuguese); Universidade do Minho; Portugal; September 2006. 